\title{
Anatomía general, histología y morfometría del sistema digestivo del pez Pterophyllum scalare (Perciformes: Cichlidae)
}

\author{
Edith Juliana Ramírez Espitia ${ }^{1}$, Hernán Hurtado Giraldo² \& Edwin Gómez Ramírez ${ }^{1 *}$ \\ 1. Universidad Militar Nueva Granada, Facultad de Ciencias Básicas y Aplicadas, Grupo de Ecotoxicología, Evolución, \\ Medio Ambiente y Conservación, Cajicá-Zipaquirá, Colombia; biojuli@gmail.com, edwin.gomez@unimilitar.edu.co \\ 2. Grupo de Neurociencia, Universidad de Santander, Colombia; her.hurtado@mail.udes.edu.co \\ * Correspondencia
}

Recibido 21-V-2020. Corregido 01-IX-2020. Aceptado 11-IX-2020.

\begin{abstract}
Gross anatomy, histology and morphometry of the digestive tract in the fish Pterophyllum scalare (Perciformes: Cichlidae). Introduction: Ornamental Angel fish (Pterophyllum scalare) is one of the main commercialized species from South America, with an important number of national and international dealers. Objective: To make a histological and morphometric description of $P$. scalare digestive tract. Methods: Nineteen adult individuals were used. Intestinal coefficient values were obtained, and a macroscopic and microscopic description of esophagus, stomach, and intestine (anterior, middle and posterior) was carried out. Samples were processed for paraffin embedding, and $5 \mu \mathrm{m}$ sections were stained with H\&E and P.A.S. Positive P.A.S. cells were counted. Lumen area and tissue area were measured in representative digitalized sections from each region. Results: P. scalare exhibited a short esophagus, followed by a blind bag shaped, scarcely muscular stomach, and a short intestine (intestinal coefficient $1.66+/-0.52$ ). Four constitutive tissue layers were identified: mucosa, submucosa, muscular and in some areas also a serosa layer. Esophagus exhibit abundant globet P.A.S. + cells and shows the larger tisular area was observed. Luminal area and perimeter are larger in anterior intestinal region. Conclusions: the intestinal coefficient value $(1.66+/-0.52)$, and the histological and morphometric characteristics of the evaluated organs, suggest that $P$. scalare is omnivorous with soft prey preferences.
\end{abstract}

Key words: teleost; goblet cells; P.A.S.; histochemistry; gut.

Ramírez Espitia, E.J., Hurtado Giraldo, H., \& Gómez Ramírez, E. (2020). Anatomía general, histología y morfometría del sistema digestivo del pez Pterophyllum scalare (Perciformes: Cichlidae). Revista de Biología Tropical, 68(4), 1371-1383.

Pterophyllum scalare, escalar o pez ángel, es un cíclido Sur Americano, originario de las Cuencas del Orinoco y del Amazonas, presenta gran demanda comercial debido a sus colores, capacidad reproductiva y adaptabilidad a la cautividad, convirtiéndolo en una de las diez especies más comercializados a nivel mundial (Agudelo, 2006). P. scalare es un pez de cuerpo discoidal, aplanado y alto, presenta boca pequeña, con aletas grandes y desarrolladas (Cruz, 2003). El adulto puede alcanzar los 15 $\mathrm{cm}$ de longitud y $25 \mathrm{~cm}$ de altura, se encuentran en aguas lentas con abundante vegetación sumergida (Salinas \& Agudelo, 2000). P. scalare prefiere alimento vivo, como; Artemia salina, Daphnia pulex, y larvas de Tubifex tubifex, Culex quinquefasciatus, Culex pipiens y el rotífero Brachionus plicatilis, sin embargo, acepta alimentos secos (Zafra \& Vela, 2015).

El sistema digestivo en peces es altamente variable entre las diferentes especies, debido a la diversidad de tipos de dietas y ambientes explotados (Dos Santos, Arantes, Santiago, \& Dos Santos, 2015). Por lo anterior, es común 
que la morfología digestiva varié directamente con el hábito alimenticio, sexo, edad, filogenia, masa corporal y forma de los peces (Day, Tibbets, \& Secor, 2014). A pesar de esto, algunas estructuras son comunes, presentando cuatro capas constitutivas: mucosa, submucosa, muscular y serosa (Guzmán, Santana, Verdugo, Gómez-Ramírez, \& Hurtado, 2013). Habitualmente el esófago es corto y ancho con una capa de músculo estriado que les permite la regurgitación de los alimentos no deseados (Faccioli, Chedid, Amaral, Franceschini, \& Vicentini, 2014). El estómago puede estar presente o ausente, denominándose gástricos o agástricos. En teleósteos este órgano se caracteriza por la aparición de glándulas gástricas, las cuales producen ácido clorhídrico y pepsinógeno (Muñoz, Caldas, \& Hurtado, 2006). El intestino presenta una pared muscular delgada y gran cantidad de pliegues en la mucosa interna especialmente hacia la región anterior (Gómez, Tovar, Obando, \& Hurtado, 2010).

A pesar de la importancia económica $P$. scalare en la acuariofilia, las principales limitaciones para su producción comercial están relacionadas con la falta de conocimientos básicos de su biología. Por tal motivo, el objetivo de este trabajo fue realizar una descripción morfológica, histológica y morfométrica del tracto digestivo (esófago, estómago e intestino) de individuos adultos del pez escalar ( $P$. scala$r e)$, que a futuro contribuya al diseño de dietas apropiadas para la especie, o a la creación de mejores planes de alimentación.

\section{MATERIALES Y MÉTODOS}

Estudio Macroscópico: 19 individuos adultos de $P$. scalare, de longitud total $8.95 \mathrm{~cm}$ $+/-1.30 \mathrm{~cm}$, fueron adquiridos con proveedores especializados de tiendas acuaristas. Se les realizó una descripción macroscópica del tracto digestivo, registrando medidas de longitud del esófago, estómago e intestino. Se calculó el coeficiente intestinal $(\mathrm{CI})$ donde $\mathrm{CI}=\mathrm{Li}^{*} \mathrm{Ls}^{-1}$ donde $\mathrm{Li}$ es la longitud intestinal $(\mathrm{cm})$ y Ls es longitud estándar (cm) (Guzmán et al., 2013). Los peces fueron anestesiados y sacrificados siguiendo los protocolos éticos para la experimentación con animales, para lo cual se utilizó MS-222, en una dosis de $0.1 \mathrm{~g} / \mathrm{L}$ (ASV, 2016). Posteriormente se realizó la disección y se obtuvieron los órganos de estudio (esófago, estómago e intestino).

Estudio Histológico: Las muestras fueron fijadas en formaldehído al $4 \%$, a una temperatura de $4{ }^{\circ} \mathrm{C}(\mathrm{pH} 7.2-7.3)$ durante tres días, deshidratadas en concentraciones crecientes de alcohol (70, 90, $95 \%)$ con tiempos de una hora cada uno y dos cambios de una hora en Isopropanol, aclaramiento en xilol e inclusión en parafina (Gómez, Obando, Tovar, Caldas, \& Hurtado, 2011). Cortes transversales de $5 \mu \mathrm{m}$ de espesor con un micrótomo SLEE CUT 4060. Tinción Hematoxilina \& Eosina (Guzmán et al., 2013) y tinción de ácido peryódico-Shiff (P.A.S) para detectar la presencia de mucinas neutras en el tracto digestivo (Faccioli et al., 2014).

Para la descripción histológica se procesaron 10 individuos. El esófago y el estómago se procesaron completos, mientras que el intestino se dividió en cuatro regiones: dos regiones anteriores ( $\mathrm{a} y \mathrm{~b}$ ), una región media y una posterior. Se capturaron imágenes con una cámara digital CANON Power Shot adaptada a un microscopio óptico (ZEISS $®$ )

Estudio Morfométrico: las muestras histológicas de 10 individuos fueron digitalizadas con ayuda del software ImageJ (Schneider, Rasband, \& Eliceiri, 2012). Se realizaron medidas de área y perímetro tanto del área tisular como área del lumen del tubo digestivo en cada región evaluada. Para la obtención del área tisular, se midió el área del tubo externamente y a este valor se le restó la medida de área del lumen. Se realizó un conteo del número de células caliciformes P.A.S. +, en la superficie epitelial. El conteo se llevó a cabo a dos cortes por región por cada individuo, a un intervalo de $25 \mu \mathrm{m}$.

Análisis estadístico: Para las variables respuesta: número de células caliciformes 
P.A.S. +, área, perímetro del lumen y área tisular se realizó una prueba de normalidad Shapiro-Wilk. Asimismo, se realizaron análisis de varianza (ANOVA) para comparar entre el número de células caliciformes P.A.S.+, área y perímetro del lumen y región tisular del tubo de cada región. Por último, se realizaron pruebas de TUKEY Kramer para determinar las diferencias entre las regiones de estudio con el software R-project 3.4.2. (R Core Team, 2016).

\section{RESULTADOS}

Descripción macroscópica: El esófago, estómago e intestino de $P$. scalare se muestra en la (Fig. 1A). El esófago se ubica en la parte anterior de la cavidad abdominal (Fig. 1B), tiene una longitud de $5.90+/-1.25 \mathrm{~mm}$ y está unido directamente al estómago. El estómago es poco musculoso, se encuentra adyacente a la región anterior del intestino en forma de una bolsa con una longitud de $9.20+/-3.00 \mathrm{~mm}$ (Fig. 1A, Fig. 1B). Contiguo al estómago se encontró una región que hace parte de la región anterior del intestino. El intestino presenta un enrollamiento inverso en forma de válvula espiral y tiene una longitud de $9.59+/-3.36 \mathrm{~cm}$. Este ocupa toda la región abdominal del pez, desde la región pilórica del estómago hasta el recto. El comienzo del recto no fue posible de diferenciar macroscópicamente. El coeficiente intestinal presento un valor de $1.66+/-0.52$.

Estudio histológico. Esófago: un órgano corto y elástico compuesto por la mucosa (M), submucosa (S) y muscular (Mus), la serosa (Se) no fue posible identificarla en esta región (Fig. 2A). El epitelio de la mucosa se deforma debido a la gran cantidad de células caliciformes (CC) (90-100 \%) presentes dentro de este, observándose gránulos de mucina (Fig. 2B). La capa de mucosa del esófago está compuesta por un epitelio plano estratificado (Epe), de 4 a 5 células de grosor (Fig. 2C). La submucosa está compuesta por tejido conectivo laxo (Fig. 2C) el cual rodea paquetes de músculo estriado longitudinal. Externamente, se encuentra la capa muscular de músculo estriado circular el cual presenta un mayor espesor que el longitudinal (Fig. 2D).

Estómago: está compuesto por mucosa, submucosa y muscular (Fig. 3A). La serosa al igual que en el esófago no fue posible identificarla. La mucosa presenta pliegues largos y gruesos (Fig. 3A) con una sola capa de células epiteliales cilíndricas sin presencia de células caliciformes a diferencia del esófago (Fig. 3B).

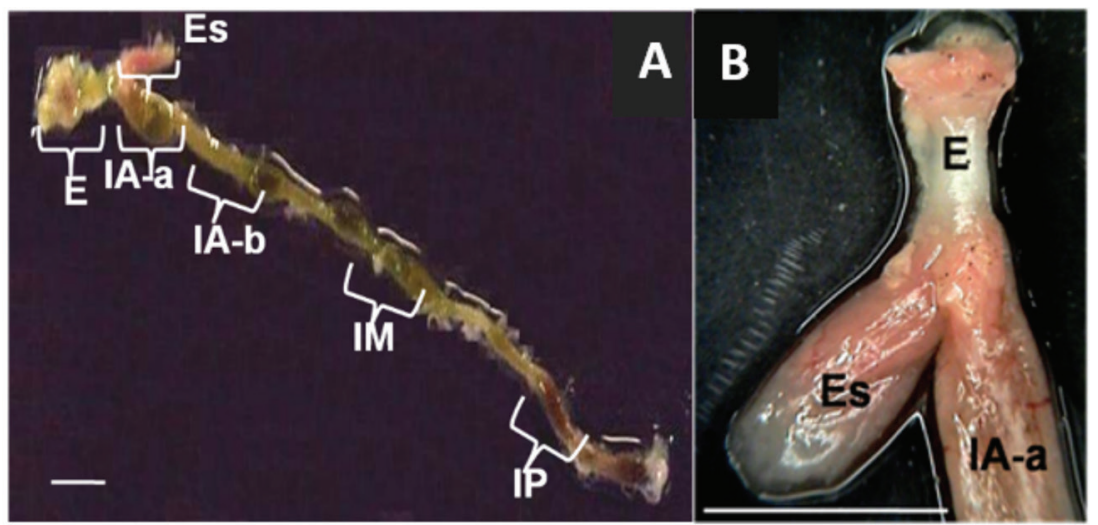

Fig. 1. Tracto digestivo de P. scalare A. Tracto digestivo: Esófago (E), Estómago (Es), Intestino anterior parte a (IA-a), Intestino anterior parte b (IA-b), Intestino Medio (IM), Intestino Posterior (IP). Barra $=1 \mathrm{~cm}$. B. Detalle de Esófago (E), Estómago (Es) e Intestino anterior parte a $(I A-a)$. Barra $=1 \mathrm{~cm}$.

Fig. 1. P. scalare intestinal tract A. Intestinal tract: Esophagus (E), Stomach (Es), Anterior intestine region a (IA-a), Anterior intestine, part b (IA-b), Middle intestine (IM), Posterior intestine (IP). Bar $=1 \mathrm{~cm}$. B. Esophagus (E), Stomach (Es) and Anterior intestine part a (IA-a) details. Bar $=1 \mathrm{~cm}$. 

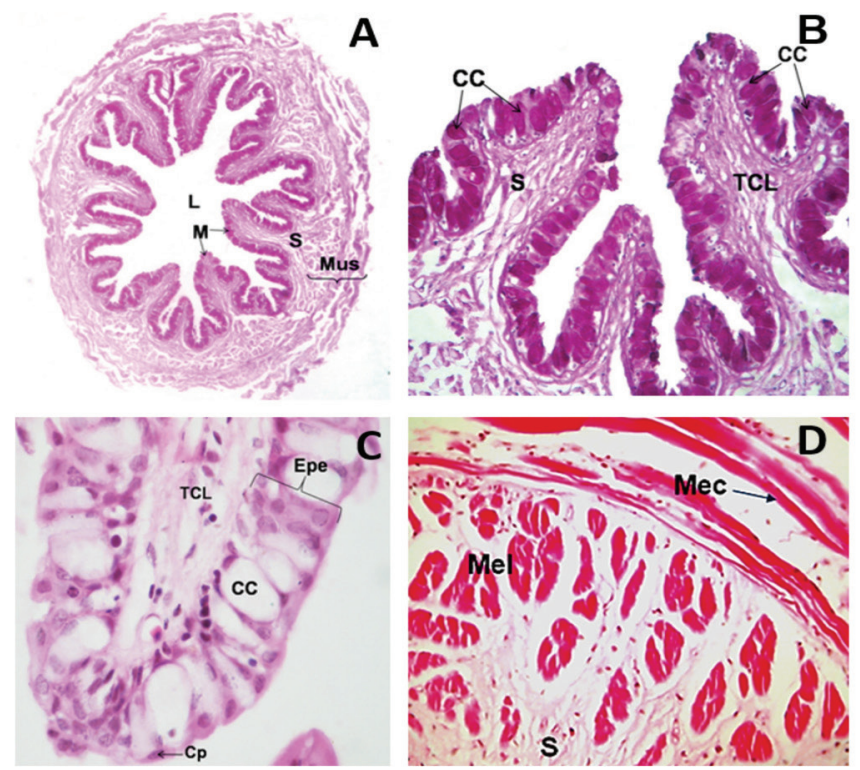

Fig. 2. A. Vista panorámica transversal del esófago. PAS. 50X. B. Pliegues y células caliciformes PAS positivas del esófago PAS. 320X. C. Detalle de la mucosa del esófago H\&E. 1300X. D. Detalle de la capa muscular del esófago, H\&E. 320X. Lumen (L), Mucosa (M), Submucosa (S), Muscular (Mus), Células caliciformes P.A.S. + (CC), Tejido conectivo laxo (TCL), Epitelio plano estratificado (Epe), Células planas (Cp) Músculo estriado circular (Mec), Músculo estriado longitudinal (Mel).

Fig. 2. A. Esophagus transversal panoramic view. PAS. 50X. B. Esophagus folds and PAS globet positive cells. PAS. 320X. C. Esophagus mucosa detail H\&E. 1300X. D. Esophagus muscular layer detail, H\&E. 320X. Lumen (L), Mucosa (M), Submucosa (S), Muscular (Mus), P.A.S. + globet cells (CC), loose connective tissue (TCL), stratified squamous epithelium (Epe), flat cells $(\mathrm{Cp})$, circular striated muscle (Mec), longitudinal striated muscle (Mel).

En la parte apical de las células epiteliales se encuentra una capa de glándulas gástricas compuestas por un epitelio cúbico simple P.A.S.+ (Fig. 3C). En la submucosa se observa tejido conectivo laxo altamente irrigado con eritrocitos nucleados (Fig. 3D). La capa muscular está compuesta por una capa interna de músculo liso circular (MLC) y una capa externa de músculo liso longitudinal (MLL), observándose la interna más gruesa que la externa (Fig. 3D).

Intestino: la histología de todas las regiones del intestino es similar, no obstante, se observan cambios en el espesor de las capas y en la altura de los pliegues. La mucosa presenta un ECS con núcleos basales acompañados por $\mathrm{CC}$ en mayor o menor cantidad dependiendo de la región. Las ECS se ubican sobre una membrana basal poco visible. La submucosa está compuesta por TCL con presencia de células de la línea linfática. La capa muscular es de menor espesor en comparación con la del esófago y exhibe una capa interna de músculo liso circular y otra externa de músculo liso longitudinal (Fig. 4A, Fig. 4B, Fig. 4C). Intestino anterior parte "a": exhibe pliegues largos, una submucosa de espesor intermedio, la cual está vascularizada con abundantes células de línea linfática (Fig. 4A, Fig. 4B, Fig. 4C). Intestino anterior parte "b": la mucosa presenta los pliegues más profundos y en la submucosa se evidencia mayor cantidad de vasos sanguíneos. Se puede identificar la capa serosa, compuesta por un epitelio plano simple y una delgada capa de tejido conectivo laxo (Fig. 4D, Fig. 4E, Fig. 4F). Intestino medio: la mucosa posee menor área luminar, y la submucosa es de mayor espesor y menos vascularizada. La serosa es muy delgada (Fig. 4G, Fig. 4H, Fig. 4I). Intestino posterior: Se reduce considerable en el tamaño 


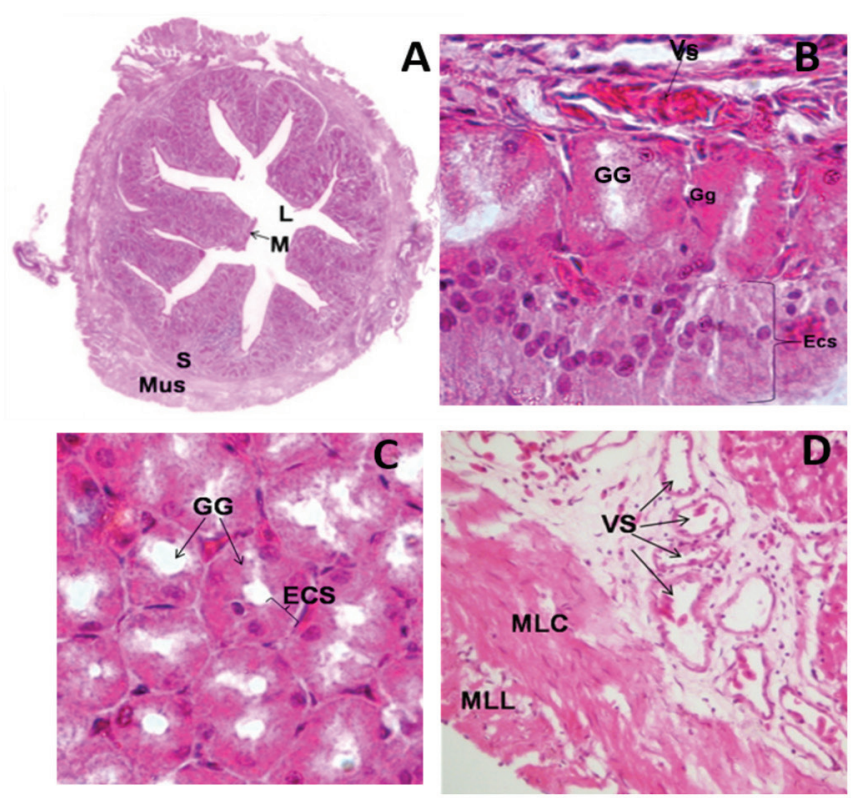

Fig. 3. A. Vista panorámica del estómago. H\&E. 1020X. B. Detalle de la mucosa del estómago H\&E. 1020X. C. Detalle de las glándulas gástricas en la mucosa del estómago H\&E. 1020X. D. Tejido conectivo laxo de la submucosa y capa muscular del estómago. H\&E. 320X. Lumen (L), Mucosa (M), Submucosa (S), Muscular (Mus), Epitelio cilíndrico simple (Ecs), glándulas gástricas (Gg), Vaso sanguíneo (VS), Músculo liso circular (MLC), Músculo liso longitudinal (MLL).

Fig. 3. A. Stomach panoramic view. H\&E. 1020X. B. Detail of stomach mucosa. H\&E. 1020X. C. Gastric glands in stomach mucosa. H\&E. 1020X. D. Submucosa loose connective tissue and stomach muscular layer. H\&E. 320X. Lumen (L), Mucosa (M), Submucosa (S), Muscular (Mus), Simple cubic epithelium (Ecs), Gastric glands (Gg), Blood vessel (VS), Circular smooth muscle (MLC), longitudinal smooth muscle (MLL).

de los pliegues, alcanzando algunos a ser planos. Las células epiteliales de la mucosa son más alargadas, y disminuye la cantidad y tamaño de células caliciformes. La submucosa es de menor grosor, aumenta la vascularización y se observan células acinares, que hacen parte de los islotes de Langerhans del páncreas (Fig. 4J, Fig. 4K, Fig. 4L).

\section{Estudio morfométrico}

Número de células caliciformes PAS positivas: El esófago fue la región del tracto digestivo que exhibió mayor número de células caliciformes PAS positivas $(943+/-353)(\mathrm{P}<$ $0.05)$, siendo las otras regiones similares entre sí. En el estómago no se encontraron células caliciformes PAS positivas (Fig. 5A).
Área del lumen: La región anterior parte "a" del intestino presentó la mayor área del lumen (Fig. 5B) exhibiendo diferencias significativas con el resto de las regiones $(\mathrm{P}<0.05)$. De igual manera las otras regiones no presentaron diferencias significativas entre ellas.

Perímetro del lumen: El intestino anterior "a", es la región con mayor perímetro del lumen (Fig. 5C) $(\mathrm{P}<0.05)$. El estómago, el intestino anterior "b", esófago e intestino medio se encuentran dentro del mismo rango sin mostrar diferencia estadística entre ellas $(\mathrm{P}<0.05)$. La región que muestra menor perímetro del lumen es el intestino posterior $(\mathrm{P}<0.05)$.

Región tisular del tubo digestivo: Las regiones que presentaron mayor área tisular 

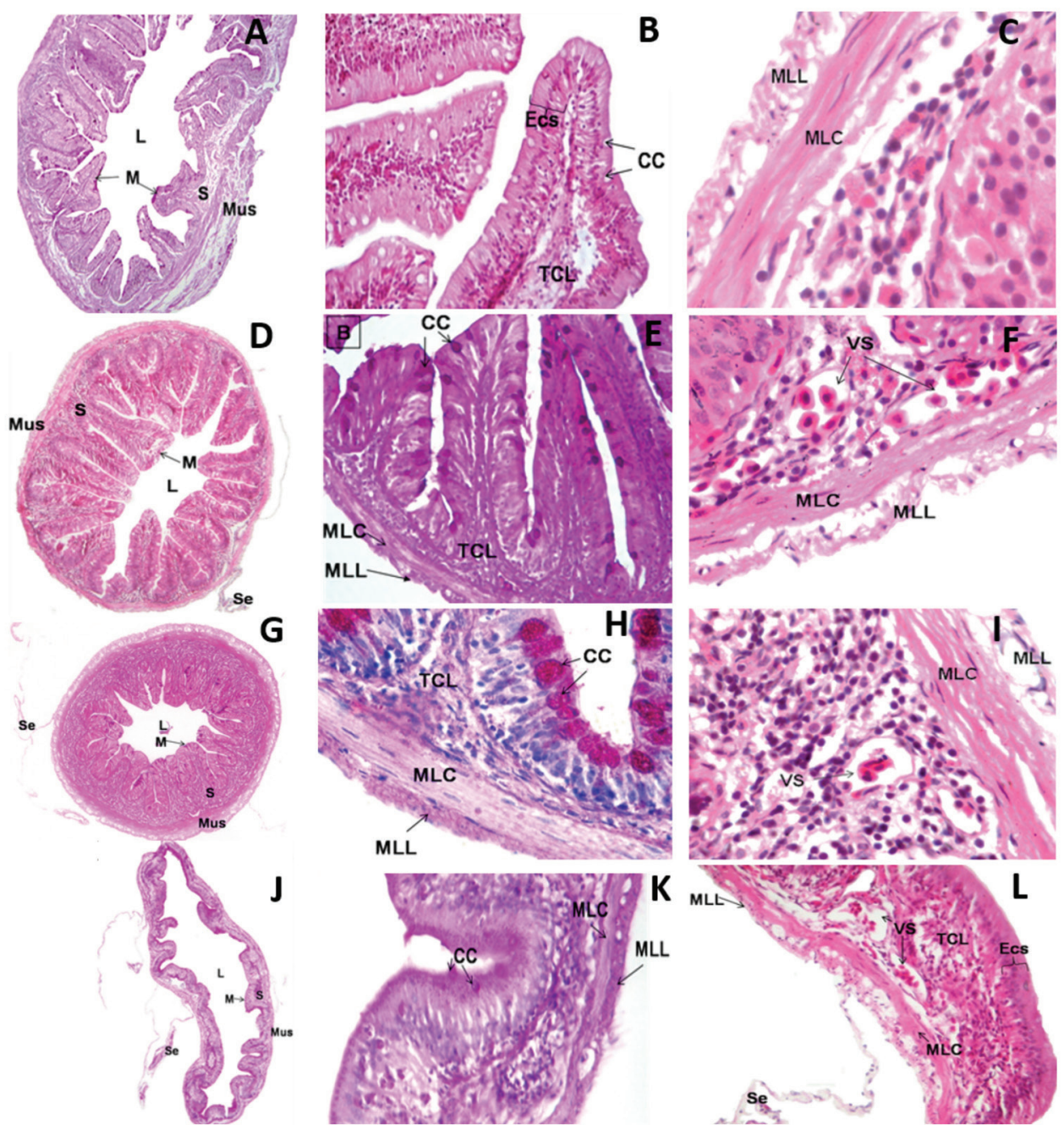

Fig. 4. A. Vista panorámica del intestino anterior parte a. P.A.S. 80X. B. Pliegues del intestino anterior parte "a". H\&E. 320X. C. Detalle de la capa muscular del intestino anterior parte "a". H\&E. 1020X. D. Vista panorámica del intestino anterior parte "b". H\&E. 80X. E. Detalle del intestino anterior parte "b" y células caliciformes. P.A.S. 520X. F. Detalle de la submucosa y capa muscular del intestino anterior parte "b". H\&E. 1020X. G. Vista panorámica del intestino medio. P.A.S. 80X. H. Detalle de células caliciformes. P.A.S. 1020X. I. Detalle de la submucosa del intestino medio. H\&E. 800X. J. Vista panorámica del intestino posterior. P.A.S. 40X. K. Pliegue del intestino posterior. P.A.S. 320X. L. Pliegue del intestino posterior. H\&E. 320X. Lumen (L), Mucosa (M), Submucosa (S), Muscular (Mus), Serosa (Se), Epitelio cilíndrico simple (Ecs), células caliciformes P.A.S.+ (CC), tejido conectivo laxo (TCL), Músculo liso circular (MLC), Músculo liso longitudinal (MLL), Vasos sanguíneo (VS).

Fig. 4. A. Panoramic view of anterior intestine part a PAS. 80X. B. Anterior intestine part a folds. H\&E. 320X. C. Detail of anterior intestine part "a", muscular layer. H\&E. 1020X. D. Panoramic view of anterior intestine part b. H\&E. 80X. E. Detail of the foregut part "b" and goblet cells. PAS. 520X. F. Detail of submucosa and muscular layer of anterior intestine part "b". H\&E. 1020X. G. Panoramic view of middle intestine. P.A.S. 80X. H. Detail of P.A.S. positive goblet cells. P.A.S. 1020X. I. Detail of middle intestine submucosa. H\&E. 800X. J. Panoramic view of posterior intestine. P.A.S. 40X. K. Posterior intestine folds. P.A.S. 320X. L. Posterior intestine fold. H\&E. 320X. Lumen (L), Mucosa (M), Submucosa (S), Muscular (Mus), Serosa (Se), Simple cylindrical epithelium (Ecs). P.A.S. + goblet cells (CC), Loose connective tissue (TCL), Circular smooth muscle (MLC), Longitudinal smooth muscle (MLL), Blood vessel (VS). 

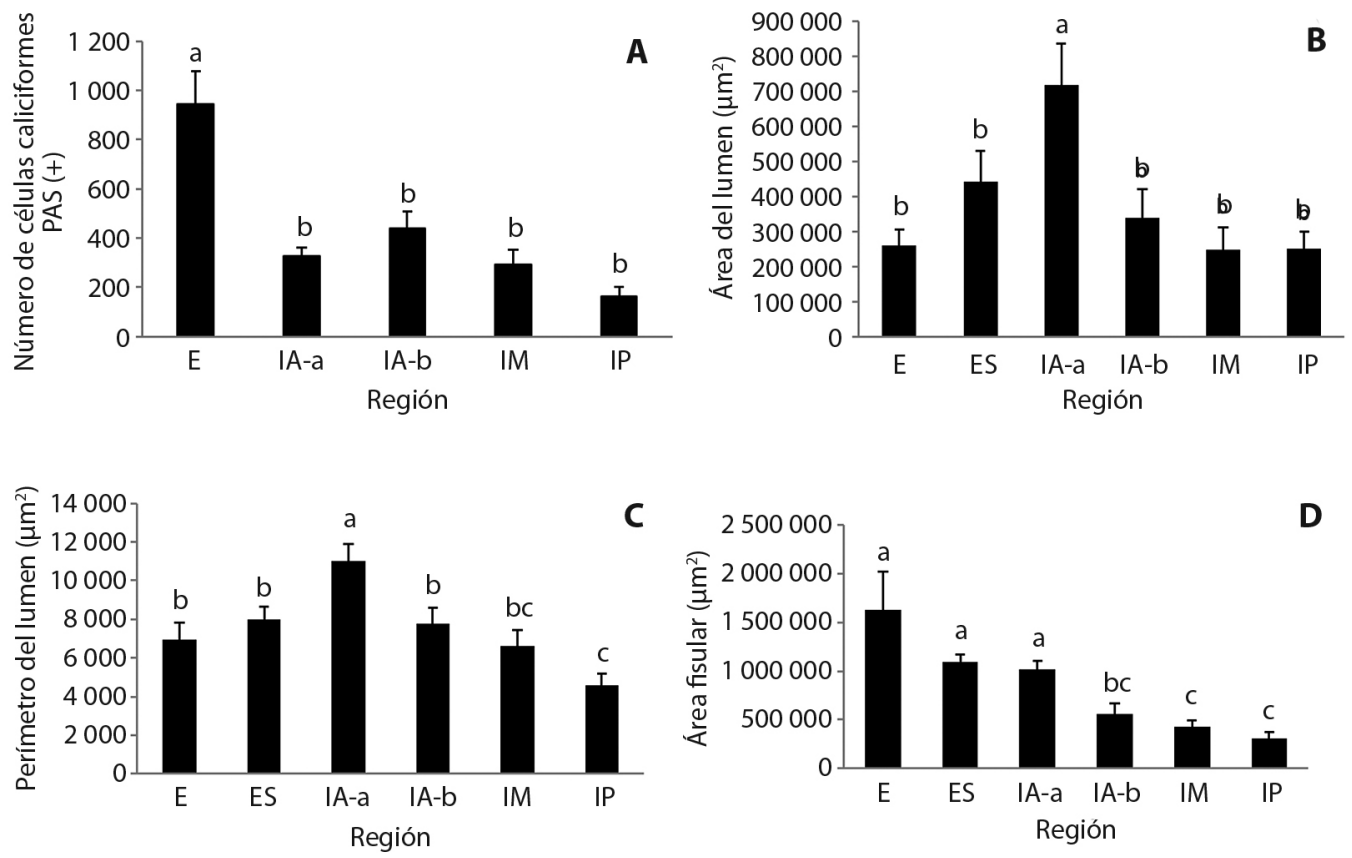

Fig. 5. A. Número de células caliciformes P.A.S.+ en diferentes regiones del tracto digestivo de P. scalare (PAS +). B. Área en micras cuadradas del lumen en las diferentes regiones del tracto digestivo de $P$. scalare. C. Perímetro en micras del lumen en las diferentes regiones del tracto digestivo de P. scalare. D. Área tisular en micras cuadradas del tubo digestivo en las diferentes regiones del tracto digestivo de $P$. scalare. Cada valor representa el promedio y el error estándar $(\mathrm{N}=10, \mathrm{P}<$ 0.05). Esófago (E), estómago (ES), región anterior del intestino parte a (IA-a), región anterior del intestino parte b (IA-b), región media del intestino (IM) y región posterior del intestino (IP) $(\mathrm{N}=10, \mathrm{P}<0.05)$.

Fig. 5. A. Goblet cells number at $P$. scalare different intestinal tract regions (PAS + ). B. Luminal area (in square micrometers) at different regions of $P$. scalare intestinal tract. C. Luminal perimeter (in microns) at different regions of $P$. scalare intestinal tract. D. $P$. scalare Intestinal tract tissular area (in square microns) at different regions. Each value represents mean $+/-$ standard error $(\mathrm{N}=10, \mathrm{P}<0.05)$. Esophagus $(\mathrm{E})$, Stomach $(\mathrm{ES})$, Anterior intestine part a (IA-a), Anterior intestine part $\mathrm{b}$ (IA-b), Middle intestine (IM) and Posterior intestine (IP) $(\mathrm{N}=10, \mathrm{P}<0.05)$.

del tubo digestivo fueron el esófago, estómago e intestino anterior parte a (Fig. 5D), mostrando diferencias significativas con el resto de las regiones evaluadas $(\mathrm{P}<0.05)$. Por otro lado, el intestino anterior "b", no mostró diferencias significativas con la región media y posterior del intestino.

\section{DISCUSIÓN}

Nivel macroscópico: La organización del tracto digestivo de $P$. scalare no presenta gran variación en comparación con otros teleósteos (Muñoz et al., 2006; Gómez et al., 2011; Guzmán et al., 2013), y comparte varias similitudes con especies de la misma familia de cíclidos, como la tilapia (Oreochromis niloticus) cuyo hábito es herbívoro (Caceci, El-Habback, Smith, \& Smith, 1997), y los omnívoros; el cíclido enano tropical (Apistogramma ramirezi) y el cíclido bandera (Mesonauta festivus) (Sánchez, Galvis, \& Victoriano, 2003).

$P$. scalare no presento ciegos pilóricos, no obstante, Medina, Martínez, Machado, Bonilla \& López (2009) mencionan que aún no hay una clara relación entre la presencia de los ciegos pilóricos y la dieta de los peces, debido a que pueden ser encontrados en peces: carnívoros, omnívoros y herbívoros. Esto es apoyado por Vásquez (2004) quien afirma que estas estructuras son vistas en aproximadamente el $60 \%$ de las especies ícticas sin importar su habito 
alimenticio. Pese a esto, otros autores afirman que son más comunes y abundantes en especies carnívoras que herbívoras, y ausentes en peces agástricos (Londoño-Franco, Laverde-Trujillo, \& Muñoz-García, 2009).

$P$. scalare presentó un coeficiente intestinal de $1.66+/-0.52$. Karachle \& Stergiou (2010) reportan que un coeficiente intestinal menor de 1 indica una dieta carnívora, mayor de 1 y hasta 3 , dietas omnívoras, mientras que valores superiores a 3 , son peces que consumen material vegetal o detritos. A partir de estos resultados se podría decir que $P$. scala$r e$ es una especie omnívora. No obstante, si solo se considera este valor se puede llegar a errores, por ejemplo; la cachama blanca (Piaractus brachypomus) presentó un valor de 1.0 (Muñoz et al., 2006) y el nicuro (Pimelodus blochii) 0.93 (Guzmán et al., 2013), indicando especies carnívoras. Sin embargo, mediante el análisis histológico llevado a cabo en este estudio se pudo determinar que se trataba de una especie omnívora.

El esófago $P$. scalare es un órgano corto y musculoso, apropiado para procesar las pequeñas presas ingeridas, como: Artemias, daphnias, rotíferos y larvas de insectos (Zafra \& Vela, 2015). La parte terminal del esófago hace su transición hacia dos regiones, una da continuidad a la primera parte del intestino y la otra al estómago en forma de un saco ciego. Este tipo de estómago también es encontrado en otros cíclidos O. niloticus (Caceci et al., 1997), M. festivus y A. ramirezi (Sánchez et al., 2003). En algunos teleósteos el estómago se divide en región cardíaca, fúndica y pilórica (Olaya et al., 2007). En P. scalare no se observó una diferenciación morfológica de estas regiones. Este pez, presentaba un estómago pequeño y poco musculoso, características que lo ubican como un pez omnívoro (Sánchez et al., 2003). El intestino por su parte presentó un enrollamiento inverso, como una válvula espiral (Guillaume, Kaushik, Bergot, \& Metailler, 2004), este plegamiento es debido al limitado espacio de la cavidad abdominal, el cual es muy comprimido lateralmente (Cruz, 2003).
Estudio histológico: A lo largo de todo el tracto digestivo de $P$. scalare, se evidencian las tres primeras capas: mucosa, submucosa y muscular. Mientras que la serosa por su espesor no se observó en el esófago y estómago. Cada una de estas capas, poseen diferencias según cada región, que demuestran especializaciones y funciones específicas (Tyagi \& Shukla, 2002). El epitelio plano estratificado en la mucosa del esófago de $P$. scalare, tiene una función de protegerse contra la abrasión (Etünkaya, Kankaya, \& Elp, 2001; Albrecht, Ferreira, \& Caramaschi, 2005). La secreción de mucus en el esófago es realizada principalmente por las numerosas células caliciformes encontradas en esta región. Esta característica es compartida con otras especies de diferentes hábitos alimenticios, y también en especies omnívoras como: $P$. pictus (Olaya et al., 2007), A. seemanni (Gómez et al., 2010), P. blochii (Guzmán et al., 2013) entre otras, y en los carnívoros: Silurus glanis L. (Petrinec, Nejedli, Kužir, \& Opačak, 2005), Paracheirodon axelrodi (Gómez et al., 2010), y Hemisorubim platyrhynchos (Faccioli et al., 2014). Las células caliciformes que se encontraron a través del tracto digestivo presentaban abundantes gránulos en su citoplasma, por lo que se deduce que estas células son de tipo A, conteniendo mucosubstancias neutras, glicoproteínas y mucosacaridos (Hernández, Pérez, $\&$ Domitrovic, 2009), lo cual es apoyado por la morfometría y la tinción P.A.S+.

Esófago: la submucosa del esófago de $P$. scalare, como la de los otros órganos evaluados presenta un tejido conectivo laxo. Esto difiere a lo presentado para el bagre omnívoro $R$. quelen o el pez filtrador Catostomus catostomus, que poseen una submucosa en el esófago con abundante tejido conectivo denso. Esta diferencia es característica de peces predadores, puesto que el tejido conectivo laxo le permite una mayor distensión, dando a la pared muscular más fuerza en los movimientos peristálticos (Gómez et al., 2010).

La capa muscular del esófago presenta fibras estriadas dispuestas en sentido longitudinal interno y circular externo, similar 
a los omnívoros R. quelen (Morrison \& Wright, 1999) y O. niloticus (Hernández et al., 2009). La presencia de músculo estriado ayuda al movimiento mecánico en la digestión, generando ondas peristálticas de contracciones voluntarias, confiriéndole al pez la capacidad de devolver el alimento, e incluso vaciar su estómago con facilidad (Guzmán et al., 2013). Esta conformación anatómica contribuye al movimiento de los pliegues, los cuales mezclan el bolo alimentario, posibilitando la acción de los ácidos gástricos en el estómago (Albrecht et al., 2005).

Estómago: a diferencia del resto de regiones evaluadas, no presento células caliciformes, siendo esto común en especies omnívoras como: P. brachypomus (Muñoz et al., 2006), $P$. pictus (Olaya et al., 2007), y P. blochii (Guzmán et al., 2013), al igual que en el carnívoro: P. axelrodi (Gómez et al., 2011). Esta ausencia se debe a que el estómago se especializa principalmente en la secreción de ácido clorhídrico y enzimas digestivas por medio de las glándulas gástricas ubicadas en la mucosa. Por tal motivo, este órgano es la única región del tubo digestivo con un contenido de ácido, que asegura la desnaturalización de las proteínas, un comienzo de hidrólisis y la eliminación de una parte de bacterias patógenas (Guillaume et al., 2004).

La parte apical de las células epiteliales son P.A.S. +, esto ha sido previamente reportado en especies omnívoras y carnívoras (Albrecht et al., 2005). Estas células P.A.S. + pudieron haberse formado a de células epiteliales del estómago o el mucus provenga de las células caliciformes del esófago (Petrinec et al., 2005). Sin embargo, independiente de su origen, la función es la misma, proteger la mucosa de los contenidos altamente ácidos del estómago y promover la rápida absorción de moléculas pequeñas como disacáridos y ácidos grasos de cadena corta (Faccioli et al., 2014).

La submucosa del estómago y las diferentes regiones del intestino exhibe numerosos vasos sanguíneos. Esta capa, contribuye al proceso de absorción, puesto que facilita el transporte de oxígeno y nutrientes hacia las células y permiten la salida de sustancias de desecho viajando a través de la serosa, lugar donde también se encuentran vasos linfáticos (Olaya et al., 2007). La capa serosa, solo fue detectable en el intestino, y de manera más evidente en el intestino anterior parte " $\mathrm{b}$ " y la región posterior, donde estaba asociada a células acinares del páncreas. En peces es común que la capa serosa sea muy delgada y en ocasiones no se puede identificar, ya que se desprende fácilmente en el proceso de disección (Gómez et al., 2011).

Las capas musculares del estómago eran delgadas, cuya función es fragmentar el alimento y mezclarlo con las secreciones gástricas, produciendo partículas más pequeñas en una masa semilíquida (Gómez et al., 2011). La capa muscular del estómago y de todas las regiones del intestino estaban compuestas por un músculo liso en dos orientaciones circular interna y longitudinal externa, lo anterior permite movimientos en varias direcciones, generando una mezcla homogénea de los alimentos y la disolución de estos, haciendo la acción enzimática más eficiente (Guzmán et al., 2013).

Intestino: próximo al estómago se encuentra una región del intestino anterior que macroscópicamente era de mayor diámetro y fue denominada región anterior parte "a". Es importante señalar que tanto la distribución de las capas, como a la conformación histológica, es similar a las otras regiones evaluadas del intestino (anterior "b", media y posterior). Los pliegues de la mucosa de la región anterior "a", "b" y media del intestino son abundantes y de mayor grosor comparativamente con los del esófago y estómago. La mucosa funciona como primera barrera de defensa contra agentes infecciosos, por lo que la acidez gástrica, el jugo pancreático, la bilis, el mucus y la motilidad intestinal, contribuyen a una mayor protección ante patógenos o sustancias nocivas (Zaldívar, 2002). La submucosa de la región anterior presenta células de tipo linfático que aumentan considerablemente en la región media. En peces el sistema inmune está conformado por el tejido linfoide asociado a la mucosa (TLAM), el cual a su vez se divide en: tejido 
linfoide asociado al tracto digestivo (TLATD), tejido linfoide asociado a la piel (TLAP) y tejido linfoide asociado a las branquias (TLAB). Sin embargo, el TLATD es el órgano del sistema inmune más importante de los teleósteos, por el número de linfocitos y la cantidad de inmunoglobulina que produce. Esto está relacionado con la gran cantidad de antígenos y las propiedades inmuno moduladoras de la TLAM, la cual no solamente le confiere defensa contra patógenos, sino que recientemente ha cobrado importancia al promover el sistema inmune a través de dietas con productos probióticos (Lazado \& Marlowe, 2014).

En la región posterior del intestino se observó una disminución considerable en el tamaño de los pliegues, con respecto a la región anterior b y media. Esto demuestra que la digestión y absorción de nutrientes es menor en esta región del intestino (Gómez et al., 2011).

Estudio morfométrico: En cuanto al análisis histoquímico de la mucosa con la tinción P.A.S., confirman que los productos de secreción de la mucosa son producidos por células caliciformes en el esófago e intestino, la parte apical de las células epiteliales del intestino y algunas glándulas en el estómago (Petrinec et al., 2005; Cinar \& Senol, 2006).

Las células caliciformes que contienen mucinas neutras son P.A.S + en contraste con las células $\mathrm{AB}$ positivas (Alcian Blue) las cuáles tienen mucinas ácidas. Las mucinas ácidas se deben a la presencia de residuos de azúcar sialil y sulfatados, mientras que las mucinas neutras poseen proteoglicanos y glicoproteínas, exhibiendo un menor contenido de sulfomucinas y sialomucinas (Nieto, Torres, Ríos, \& Gil, 2002). El esófago, fue la región con mayor número de células caliciformes P.A.S + presentando diferencias significativas con el resto de las regiones. Esto indica que esta región genera una mayor secreción de mucus, desempeñando un papel de protección mecánica, antimicrobiana y antiviral (Ostaszewskaa, Dabrowski, Palácios, Olejniczaka, \& Wieczoreka, 2005). Lo que a su vez incrementa la degradación proteolítica de microorganismos patógenos, al evitar la adherencia de bacterias a las células epiteliales, previniendo así la colonización de la mucosa por agentes patógenos (Cinar \& Senol, 2006). Por otro lado, estas células cumplen funciones osmorregulatorias, formando una barrera difusora para varios iones y protegiéndolos contra la acidez excesiva (Petrinec et al., 2005). El mayor número de estas células hallado en el esófago, puede ser explicado a la carencia de glándulas salivares por parte de los peces, y estas mucosustancias facilitarían el movimiento de partículas de mayor tamaño (presas enteras), evitando así, un daño mecánico de los epitelios (Gisberta, Piedrahita, \& Douglas, 2004).

Las otras regiones estudiadas no presentan diferencias significativas en cuanto al número de células caliciformes P.A.S +. Sin embargo, en teleósteos, las células caliciformes pueden ser abundantes en otras regiones del intestino. Tal es el caso del Ciprínido herbívoro Labeo horie que posee una mayor cantidad de células caliciformes en la región anterior, pues al tratarse de un pez que consume gran cantidad de residuos sólidos duros y secos, necesita de una alta lubricación en esta región (Albrecht et al., 2005). En el caso del pez omnívoro P. pictus, o de los peces carnívoros $O$. mykiss y $P$. axelrodi por ejemplo, se observa un aumento de células caliciformes en la parte posterior del intestino, característica atribuible a peces con intestinos cortos, que necesitan aumentar la producción de mucus para evitar la abrasión por la acumulación de heces (Young, Heath, \& Wheater, 2000; Olaya et al., 2007; Gómez et al., 2011). En el caso de $P$. scalare y el tiburoncito $A$. seemanni se observa una distribución homogénea de estas células a lo largo del intestino, lo que coincide con especies que consumen alimentos blandos que no requieren de una lubricación extra (Gómez et al., 2010). Las células caliciformes en el intestino no solo cumplen funciones de prevención del daño mecánico, ya que son importantes para prevenir la inflamación intestinal, esto explicaría por qué no se presentaron diferencias significativas a lo largo del intestino (Nieto et al., 2002). 
En cuanto al área y perímetro luminar, la región del intestino (IA-a), presenta diferencias significativas con las otras regiones. Lo anterior indica que esta región posee un gran espacio para recibir el alimento sobrante y seguir hacia el resto del intestino. Esto indica que, si la alimentación es la adecuada, esta región brindaría una alta absorción por una mayor área y un mayor perímetro luminar, asimilando de mejor manera el alimento ya digerido por el estómago. Sin embargo, si se maneja una inapropiada alimentación, es decir alta cantidad de alimento, el estómago se llenaría rápidamente y el alimento restante pasaría directamente al intestino, sin predigestión, disminuyendo así la eficiencia alimenticia, como puede ocurrir en especies con tractos digestivos similares como O. niloticus (Caceci et al., 1997).

A pesar de que el esófago no mostró diferencias significativas con el estómago, y el intestino anterior parte $\mathrm{b}$, media y posterior, se debió a que el esófago se encontraba más ocluido que el resto de los órganos, esta morfología evita la excesiva ingestión de agua, cerrándose herméticamente una vez ingiere el alimento (Argumedo \& Rojas, 2000).

El perímetro luminal del esófago, estómago, intestino anterior parte " $b$ " y media, no presenta diferencias significativas. A pesar de esto, los pliegues profundos y gruesos de la mucosa, permiten aumentar la superficie de contacto con el sustrato alimentario, favoreciendo la digestión (Gómez et al., 2011). Por otro lado, la región posterior muestra diferencias con las otras regiones, lo cual se observa en los pliegues cortos en comparación con las otras regiones, indicando una menor absorción por esta región.

La región tisular del esófago, estómago e intestino anterior parte "a", presentan mayor área, sin diferencias significativas entre ellas, pero si con las otras regiones del intestino. El esófago y el estómago se caracterizan por tener una mayor capa muscular y pliegues largos, lo que podría explicar este valor. Esta mayor área o espesor en la capa muscular es común en especies omnívoras como: P. brachypomus (Muñoz et al., 2006), P. pictus (Olaya et al., 2007),
P. blochii (Guzmán et al., 2013) y Brycon siebenthale (Vásquez, 2004). Estas características de la mucosa y la capa muscular en el estómago, facilita los movimientos peristálticos más fuertes y mayor acción mecánica. Por el contrario, las regiones del intestino que presentan las menores áreas en la región tisular, son debidas a la reducción de la capa muscular, la cual no requiere de movimientos peristálticos fuertes (Gómez et al., 2010).

Declaración de ética: los autores declaran que todos están de acuerdo con esta publicación y que han hecho aportes que justifican su autoría; que no hay conflicto de interés de ningún tipo; y que han cumplido con todos los requisitos y procedimientos éticos y legales pertinentes. Todas las fuentes de financiamiento se detallan plena y claramente en la sección de agradecimientos. El respectivo documento legal firmado se encuentra en los archivos de la revista.

\section{AGRADECIMIENTOS}

A la Universidad Militar Nueva Granada y su Vicerrectoría de Investigaciones. A Martha Janeth Obando y María Leonor Caldas.

\section{RESUMEN}

Introducción: El pez escalar (Pterophyllum scalare) es una de las principales especies de peces ornamentales comercializados de Sur América. Objetivo: describir histológica y morfométricamente el tracto digestivo del pez tropical P. scalare. Métodos: se utilizaron 19 individuos adultos, y se calculó el coeficiente intestinal. Se realizó una descripción macroscópica e histológica del esófago, estómago e intestino (región anterior parte a, anterior parte $\mathrm{b}$, media y posterior). Las muestras fueron procesadas en parafina, se obtuvieron cortes de $5 \mu \mathrm{m}$, que fueron teñidos con H\&E y P.A.S. Se realizó conteo de células P.A.S +. Para la morfometría se digitalizaron los cortes y se midió el área y perímetro del lumen, y el área tisular para cada región. Resultados: $P$. scalare presenta un esófago corto, un estómago en forma de saco ciego poco muscular junto a un intestino con una longitud similar a su tamaño, coeficiente intestinal (1.66 +/- 0.52). Se identificaron cuatro capas constitutivas: mucosa, submucosa, muscular y en algunas regiones serosa. El esófago se destacó por ser la región con mayor número de células caliciformes 
P.A.S. + y mayor área tisular. En cuanto al área y perímetro luminar, la región anterior parte a del intestino fue la de mayor valor. Conclusiones: a partir del coeficiente intestinal (1.66+/- 0.52), y las características histológicas y morfométricas de los órganos evaluados, se puede decir que $P$. scalare presenta un hábito alimenticio omnívoro con preferencia de presas blandas.

Palabras clave: teleósteos; células caliciformes; P.A.S.; histoquímica; intestino.

\section{REFERENCIAS}

Agudelo, A.G. (2006). Establecimiento de un centro de reproducción de Pterophyllum Scalare (pez ángel o escalar). Revista La Sallista de Investigación, 2(2), 26-30.

Albrecht, M., Ferreira, M., \& Caramaschi, E. (2005). Anatomical features and histology of the digestive tract of two related neotropical omnivorous fishes (Characiformes; Anostomidae). Journal of Fish Biology, 58(2), 419-430.

Argumedo, T., \& Rojas, H. (2000). Manual de piscicultura con especies nativas. Asociación de Acuicultores del Caquetá (ACUICA) y Plan Nacional de Desarrollo Alternativo (PNDA) (1 ra Ed.). Florencia, Colombia: PNDA.

ASV. (2016). The Association of Shelter Veterinarians' 2016 Veterinary Medical Care Guidelines for SpayNeuter Programs. Journal of the American Veterinary Medical Association, 249(2), 165-188. DOI: 10.2460/ javma.249.2.165

Caceci, T., El-Habback, H., Smith, S., \& Smith, B. (1997). The stomach of Oreochromis niloticus has three regions. Journal of Fish Biology, 50(5), 939-952.

Cinar, K., \& Senol, N. (2006). Histological and histochemical characterization of the mucosa of the digestive tract in Flower Fish (Pseudophoxinus antalyae). Anatomia Histologia Embryologia, 35(3), 147-151.

Cruz, O.M. (2003). Efecto de la densidad de cultivo sobre el crecimiento del escalar (Pterophyllum scalare) durante el periodo de levante en acuarios (Tesis de pregrado). Universidad Nacional de Colombia, Colombia.

Day, R.D., Tibbetts, I.R., \& Secor, S.M. (2014). Physiological responses to short-term fasting among herbivorous, omnivorous, and carnivorous fishes. The Journal of Comparative Physiology B, 184(4), 497-512.

Dos Santos, M.L., Arantes, F.P., Santiago, K.B., \& Dos Santos, J.E., (2015). Morphological characteristics of the digestive tract of Schizodon knerii (Steindachner, 1875), (Characiformes: Anostomidae):
An anatomical, histological and histochemical study. Anais da Academia Brasileira de Ciências, 87(2), 867-878.

Etünkaya, O., Kankaya, E., \& Elp, M. (2001). Histological study of the organogenesis of the digestive system and swim Bladder of the Chalcalburnus tarichi Pallas, 1811 (Cyprinidae). Turkish Journal Zoology, 25(2), 217-228.

Faccioli, C.K., Chedid, R.A., Amaral, A.C., Franceschini, I.B., \& Vicentini, C.A. (2014). Morphology and histochemistry of the digestive tract in carnivorous freshwater hemisorubim platyrhynchos (Siluriformes: Pimelodidae). Micron, 64, 10-19.

Gisberta, E., Piedrahita, R., \& Douglas, E. (2004). Ontogenetic development of the digestive system in California halibut (Paralichthys californicus) with notes on feeding practices. Aquaculture, 232(1), 455-470.

Gómez, E., Obando, M.J., Tovar, M.O., Caldas, M.L., \& Hurtado, H. (2011). Estudio histológico del tracto digestivo del neón cardenal Paracheirodon axelrodi (characidae). International Journal of Morphology, 29(3), 782-786.

Gómez, E., Tovar, O., Obando, M.J., \& Hurtado, H. (2010). Estudio histológico del tracto digestivo del pez tiburoncito Ariopsis seemanni. Revista Facultad De Ciencias Básica, 6(2), 216-225.

Guillaume, J., Kaushik, S., Bergot, P., \& Metailler, R. (2004). Nutrición y alimentación de peces y crustáceos (1a Ed.). Madrid, España: Ediciones Mundi-Prensa.

Guzmán, L., Santana, V., Verdugo, M.H., Gómez-Ramírez, E., \& Hurtado, H. (2013). Descripción anatómica e histológica del tracto digestivo de Nicuro Pimelodus blochii (Valenciennes, 1840). Orinoquia, 17(1), 102-110.

Hernández, D.R., Pérez, M., \& Domitrovic, H.A. (2009). Morphology, Histology and Histochemistry of the Digestive System of South American Catfish (Rhamdia quelen). International Journal of Morphology, 27(1), 105-111.

Karachle, P.K., \& Stergiou, K.I. (2010). Intestine morphometrics of fishes: a compilation and analysis of bibliographic data. Acta Ichthyologica Et Piscatoria, 40(1), 45-54

Lazado, C.C., \& Marlowe, C.A. (2014). Mucosal immunity and probiotics in fish. Fish \& Shellfish Immunology, 39(1), 78-89.

Londoño-Franco, L.F., Laverde-Trujillo, L.M., \& MuñozGarcía, F.G. (2017). Anatomical and histological description of the digestive tract of the sabaleta (Brycon henni). Revista de Investigaciones Veterinarias del Perú, 28(3), 490-504. 
Medina, Z., Martínez, T., Machado, A., Bonilla, A., \& López, H. (2009). Anatomía e histología de los ciegos pilóricos en cinco especies de peces de la familia Characidae. Revista Cientifica, 19(6), 607-618.

Morrison, C., \& Wright, J. (1999). A study of the histology of the digestive tract of the Nile tilapia. Journal of Fish Biology, 54(3), 597-606.

Muñoz, A., Caldas, M.L., \& Hurtado, H. (2006). Análisis histomorfométrico del sistema digestivo y glándulas anexas de alevino de cachama blanca. Revista Facultad De Ciencias Básicas, 2(1), 33-45.

Nieto, N., Torres, M., Ríos, A., \& Gil, A. (2002). Dietary polyunsaturated fatty acids improve histological and biochemical alterations in rats with experimental ulcerative colitis. The Journal of Nutrition, 132(1), 11-19.

Olaya, M.C., Ovalle, C., Gómez, E., Rodríguez, D., Caldas, M., \& Hurtado, H. (2007). Histología y morfometría del sistema digestivo del silúrido bagre tigrito (Pimelodus pictus). Revista de la Facultad de Medicina Veterinaria y de Zootecnia, 54(1), 311-323.

Ostaszewskaa, T., Dabrowski, K., Palácios, M., Olejniczaka, M., \& Wieczoreka, M. (2005). Growth and morphological changes in the digestive tract of rainbow trout (Oncorhynchus mykiss) and pacú (Piaractus mesopotamicus) due to casein replacement with soybean proteins. Aquaculture, 245(1), 273-286.

Petrinec, Z., Nejedli, S., Kužir, S., \& Opačak, A. (2005). Mucosubstances of the digestive tract mucosa in northern pike (Esox lucius L.) and european catfish (Silurus glanis L.). Veterinarski Arhiv, 75(4), 317-327.
R Core Team. (2016). $R$ : A language and environment for statistical computing. $R$ Foundation for Statistical Computing. Vienna, Austria. Retrieved from https:// www.R-project.org

Salinas, C.Y., \& Agudelo, C.E. (2000). Peces de importancia económica en la Cuenca Amazónica Colombiana (1ra ed.). Bogotá, Colombia: Editorial Scripto.

Sánchez, R.M., Galvis, G., \& Victoriano, P. (2003). Relación entre características del tracto digestivo y los hábitos alimentarios de peces del río Yucao, sistema del río Meta (Colombia). Gayana, 67(1),75-86.

Schneider, C.A., Rasband, W.S., \& Eliceiri, K.W. (2012). NIH Image to ImageJ: 25 years of image analysis. Nature Methods, 9(7), 671-675.

Tyagi, R., \& Shukla, A. (2002). Anatomy of fishes $\left(5^{\text {th }}\right.$ Ed.). New Delhi, India: Anmol Publications PUT LTD.

Vásquez, W. (2004). Principios de nutrición aplicada al cultivo de peces (1 ra Ed.). Villavicencio, Colombia: Editorial Juan XXIII.

Young, B., Heath, J., \& Wheater, P. (2000). Wheater. Histología funcional: Texto y Atlas en color (3ra Ed.). Sevilla, España: Editorial Harcourt.

Zafra, A.T., \& Vela, K.A. (2015). Producción de semilla de Pterophyllum scalare pez ángel en sistema cerrado, Trujillo-Perú. Revista Cientifica de la Facultad de Ciencias Biológicas, 35(1), 91-98.

Zaldívar, M. (2002). El sistema inmunológico de las mucosas. Revista Cubana de Medicina General Integral, l18(5), 352-354. 